\title{
TRABAJO ESTABLE EN MÉXICO: ESTUDIO COMPARATIVO ENTRE 2007 Y 2009*
}

\author{
VERÓNICA MURGUÍA SALAS \\ UNIVERSIDAD AUTÓNOMA DEL ESTADO DE MÉXICO
}

Recibido/ Received/ Recebido: 12/12/2012 - Aceptado/ Accepted/Aprovado: 15/04/2013

\begin{abstract}
Resumen
Este artículo compara las características sociodemográficas y laborales de la población en edad de trabajar en México entre los años 2007 y 2009 buscando detectar si la crisis económica que inició en el país a partir de 2008 fue catalizadora de cambios en las condiciones laborales de personas que tienen un empleo estable. Entre los principales resultados se encuentra que uno de los aspectos de mayor afectación fue la reducción de prestaciones y de ingresos de la población ocupada de 2009 con respecto a la de 2007, principalmente en algunos grupos como mujeres, jóvenes y mayores de 60 años, solteros, quienes tienen menor escolaridad, que desempeñan actividades manuales y principalmente aquellos que laboran en la industria manufacturera y el sector secundario. A pesar de esta reducción en ingresos y prestaciones, las regulaciones laborales mexicanas vigentes en el período de estudio protegieron a los trabajadores estables de perder su empleo después de la crisis económica de 2008.
\end{abstract}

Palabras clave: Estabilidad laboral, Crisis económica, Población ocupada.

\section{STEADY WORK IN MEXICO: A COMPARATIVE STUDY BETWEEN 2007 AND 2009}

\begin{abstract}
This article compares sociodemographic and occupational characteristics of working-age population in Mexico between 2007 and 2009, seeking to detect if the economic crisis that started in the country from 2008 was a catalyst for changes in working conditions of people with steady employment. Among the main results is that one of the most affected areas was the reduction of benefits and incomes of employed population in 2009 compared to 2007, mainly in groups such as women, youth and older than 60 years old, single, less educated, those who develop manual activities and those who work in manufacturing industry and secondary sector. Despite this reduction in incomes and benefits, Mexican labor regulations in force in the period of study protected the steady workers in order to not lose their jobs, after economic crisis of 2008.
\end{abstract}

Keywords: Labor stability, Economic crisis, Working population.

Resultado de investigación de la Maestría en Población y Desarrollo por la FLACSO cede México, VII promoción.

Profesora de Asignatura en la Facultad de Ciencias Políticas y Sociales de la Universidad Autónoma del Estado de México. Licenciada en Antropología Social por la UAEMex; Maestra en Población y Desarrollo por la FLACSO-México y alumna del Doctorado en Antropología Social por la Universidad Iberoamericana. Correo electrónico: mumurguias@uaemex.mx 


\title{
TRABALHO ESTÁVEL NO MÉXICO: ESTUDO COMPARATIVO ENTRE 2007 E 2009
}

\begin{abstract}
Resumo
Este artigo compara as características sóciodemográficas e laborais da população em idade de trabalhar no México entre os anos 2007 e 2009, procurando detectar se a crise econômica que começou no país a partir de 2008 foi catalizadora de mudanças nas condições laborais de pessoas que têm um emprego estável. Entre os principais resultados se encontra que um dos aspectos de maior consequência foi a redução de pagamentos de encargos sociais e de receitas da população ocupada de 2009 com relação à de 2007, principalmente em alguns grupos como mulheres, jovens e maiores de 60 anos, solteiros, com menor escolaridade, que desempenham atividades manuais e principalmente aqueles que trabalham na indústria manufatureira e no setor secundário. Apesar desta redução em receitas e encargos sociais, as regulamentações trabalhistas mexicanas vigentes no período estudado protegeram aos trabalhadores estáveis para que não perdessem seu emprego depois da crise econômica de 2008.
\end{abstract}

Palavras chave: Estabilidade trabalhista, Crise econômica, População ocupada.

Murguía, V. (2013) Trabajo estable en México. Estudio comparativo entre 2007 y 2009. En: Revista de la Facultad de Ciencias Económicas de la Universidad Militar Nueva Granada. rev. fac.cienc.econ, XXI (1)

JEL: J21, J82.

\section{Introducción}

El Banco Interamericano de Desarrollo (BID) señala que América Latina cuenta con las leyes laborales más protectoras en comparación con el resto del mundo, pero también destina una proporción mucho menor de su PIB en gasto social, incluyendo políticas de mercado de trabajo. Para ello, realizó un índice de condiciones de empleo, donde los valores más altos indican reglas más rígidas de protección a los trabajadores. Es importante señalar que el índice evalúa la ley según este escrita, sin considerar si se cumple o no (indicador de jure). El resultado al que llega, es que los países menos desarrollados son quienes tienen condiciones de trabajo más reglamentadas. De esta manera, Bolivia, Venezuela, Brasil y Panamá son los países con regulaciones más protectoras, en cambio, Jamaica, Uruguay y Chile, tienen normas más flexibles (BID, 2004). El caso de México se encuentra en una posición intermedia en cuanto a las condiciones de empleo como se puede ver en el Ilustración 1, pero es uno de los países más altos en cuanto a la rigidez de contratación y despido.

Ilustración 1. Índice de condiciones de empleo.

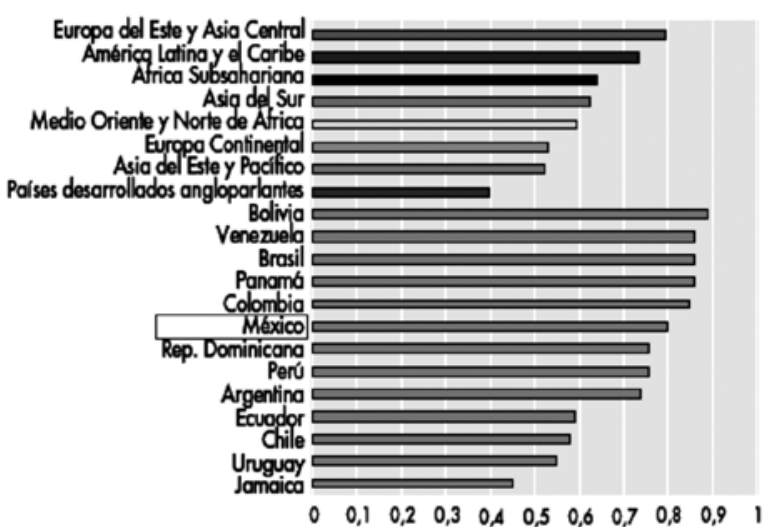

La rigidez en las regulaciones laborales está relacionado con la promoción de la estabilidad laboral, donde "el modelo mexicano impone fuertes res-

1 Fuente: BID (2004). 
tricciones a la libertad contractual, promoviendo relaciones laborales permanentes o que perduran mientras subsista la materia de trabajo a través de reglas que buscan eliminar a toda costa la discrecionalidad del empleador en la determinación de la duración de la relación de trabajo. La regla es que la relación sea por tiempo indeterminado" (Bensusán, 2006, 322).

La estabilidad laboral en México se presenta a través de seis medios: i) no existe un preaviso como en otros códigos laborales de América Latina, pero sí se exige un aviso por escrito; ii) se tiene que especificar la causa que justifique el despido; iii) se debe indemnizar al trabajador (20 días por cada año de servicio en caso de no existir reinstalación más tres meses de salario); iv) se limita el uso de contratos laborales que pueden rescindirse sin costo alguno; v) se debe consultar anticipadamente con las autoridades en caso de despidos colectivos y; vi) en caso de efectuarse un despido sin causa justa, se tiene derecho a la reinstalación, salvo las excepciones que establece la ley (BID, 2004; Bensusán, 2006).

Las condiciones anteriores provocan que el costo de los despidos para los empleadores sea alto, dando como resultado menos despidos en momentos de crisis, pero también, menores contrataciones en tiempos de expansión y mayores dificultades para conseguir trabajo por parte de quienes están desempleados (BID, 2004).

Los hechos en el mercado laboral de México evidencian contrastes significativos en cuanto a los objetivos de la regulación, puesto que en los últimos 30 años se han propuesto modificaciones para apoyar a los empresarios con el fin de incentivar la inversión en el país, liberándolos de costos en la materia y ampliando la flexibilidad laboral. Dichos cambios no han sido plasmados en la regulación hasta el momento ${ }^{2}$, más bien se han forjado como actos alternos a la ley por medio del deterioro de los sindicatos y los contratos colectivos, la inspección del trabajo y la conciliación y arbitraje.

Las acciones enfocadas a responder la demanda de mayor flexibilidad laboral en un escenario económico competitivo, implica, como algunos especialistas señalan (De la Garza y Toledo, 2011a, 2011b), una creciente precarización de los trabajos y el deterioro de los salarios reales porque no se han adoptado mecanismos como los seguros de desempleo y de retiro para proteger a los trabajadores ante las altas tasas de desocupación ${ }^{3}$.

\section{Metodología}

Esta investigación realiza un análisis comparativo de las características sociodemográficas y laborales de la población en edad de trabajar en México entre los años 2007 y 2009, con la intención de detectar si la crisis económica que inició en el país a partir de 2008, fue catalizadora de cambios en las condiciones laborales de personas que tienen un empleo estable. En los datos obtenidos, se esperaría no encontrar modificaciones en las condiciones del grupo de estudio, puesto que es el sector de trabajadores, el que está más protegido por la ley e implica altos costos de despido para el empleador.

Para lograr el objetivo, se realizó un análisis cuantitativo con observaciones de tipo transversal (stock de individuos en un momento del tiempo) de la Encuesta Nacional de Ocupación y Empleo (ENOE) de los años referidos que elabora el Instituto Nacional de Estadística y Geografía (INEGI) ${ }^{4}$.

En el análisis comparativo se estudian las características particulares de los siguientes grupos:

2 El pasado 28 de septiembre de 2012 se aprobó la Reforma Laboral por parte de la Cámara de Diputados, la cual tiene cuatro principales rubros: i) facilitar a las empresas emplear o despedir trabajadores por medio de la ampliación de las modalidades de contratación; ii) poner los salarios en función de la productividad; iii) permitir la movilidad de los empleados entre categorías dentro de la misma empresa y; iv) subcontratar. Para que la reforma laboral sea constitucional, requiere continuar con otras etapas como la aprobación de la Cámara de Senadores.

3 La tasa de desocupación anual en México del año 2007 fue de 3,72\% y en 2009 de 5,47\% (INEGI, 2007).

4 Además de obtener observaciones de tipo transversal, el diseño de la ENOE también permite recabar datos de tipo longitudinal, estos es, selecciona una muestra de hogares que son entrevistados durante cinco trimestres consecutivos, con lo cual se puede reconstruir las trayectorias laborales de individuos por 15 meses y analizar desde otra perspectiva la dinámica del mercado laboral en México, situación que por el momento no es objetivo del presente artículo. 
i) población económicamente activa, ii) población ocupada, iii) trabajadores subordinados y remunerados por modalidad de contratación y, iv) trabajadores subordinados y remunerados por tipo de contrato escrito.

En cada uno de ellos, se enfatizan las variables sociodemográficas (sexo, edad, estado civil y nivel de instrucción) y económicas (rama, sector de actividad, tamaño de establecimiento, grupo de ocupacional, posición en el trabajo, nivel de ingreso y prestaciones).

\section{Resultados: características sociodemográficas y laborales de la población de 2007 y 2009}

En México, para 2007, la población de 14 o más años de edad era de 75.751.194 individuos de los cuales el 53,2\% eran mujeres y el $46,8 \%$ hombres. En 2009, la población incrementó a 78.718.334 personas, siendo el 52,6\% mujeres y $47,4 \%$ hombres. Esta es la población que constituye el universo de estudio, observando su distribución para ambos años en la Ilustración 2 .

La población de 14 o más años se clasifica en dos grandes categorías: la Población Económicamente Activa (PEA), la cual consta de todos aquellos individuos que en el periodo de referencia declararon haber realizado una actividad económica o la buscaron activamente y; la Población No Económicamente Activa (PNEA), está conformada por aquellas personas que durante el periodo de referencia no realizaron ninguna actividad económica ni la buscaron. La PEA de 2007 era de 44.411 .852 personas y la de 2009 de 45.708.355, lo que representa poco más del $58 \%$ de la población de 14 o más años de edad, quedando el $41 \%$ como PNEA.

Ilustración 2. Distribución de la población de 14 o más años de edad en 2007 y 2009.²

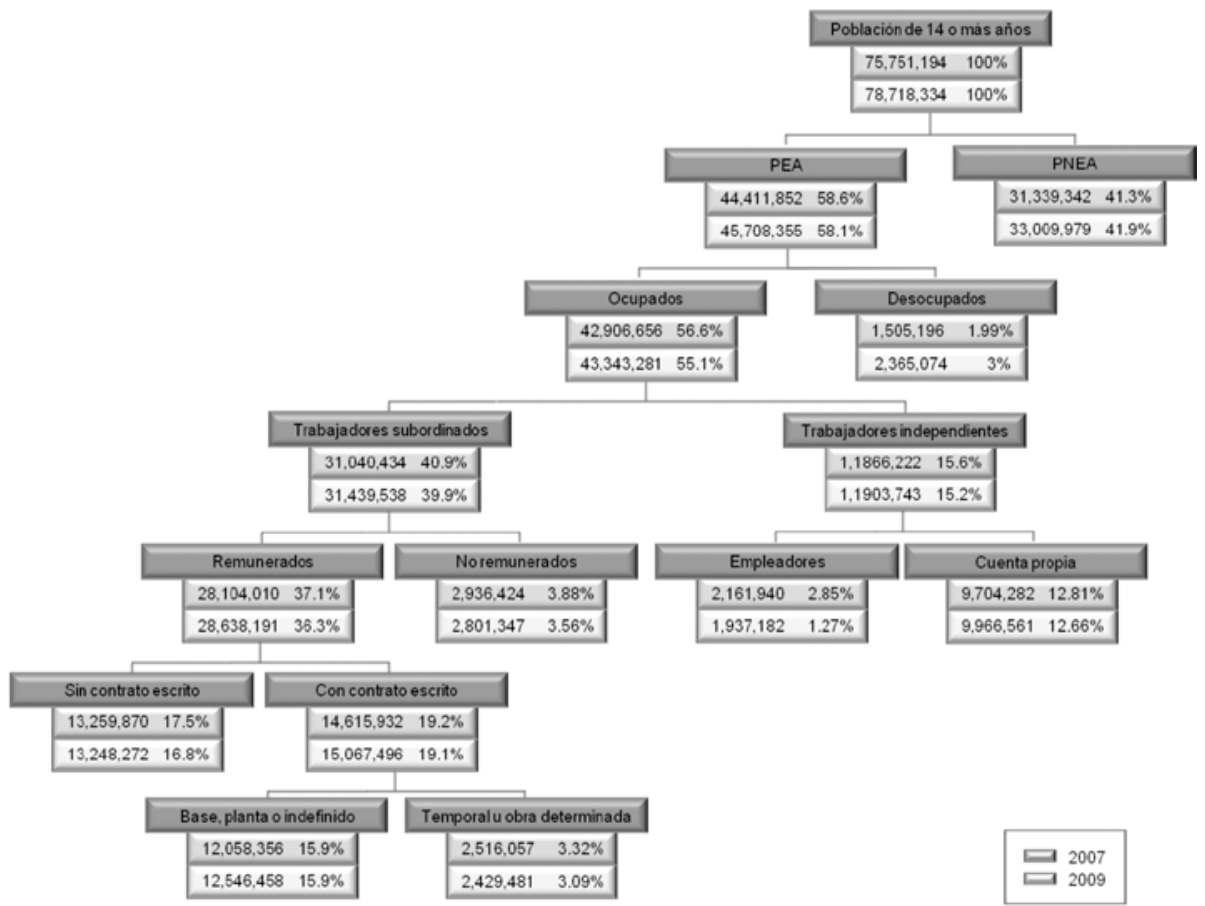

2 Fuente: Elaboración propia con base a los datos del segundo trimestre de 2007 y 2009 de la ENOE. 
En la Tabla 1 muestra que del total de las mujeres de 14 o más años de edad en 2007 que eran 40.291.137, el $41,4 \%$ se ubicaba como PEA y el $58,6 \%$ como PNEA y en 2009, siendo 41.394.701 mujeres, la proporción se mantiene semejante. En el caso de los hombres existe una variación, puesto que en 2007 eran 35.460.057, de los cuales el 78,2\% era PEA y 21,8\%, PNEA. De los 37.323.633 de hombres en 2009 , el porcentaje de la PEA fue de $76,8 \%$ y de la PNEA de 23,2\%, lo que significa que la PEA masculina disminuyó en 2009 con respecto a 2007, afectando a aproximadamente medio millón de hombres.

\subsection{Población Económicamente Activa}

\subsubsection{Características sociodemográficas}

Al considerar el 41,4\% de la PEA femenina en 2007 y $41,2 \%$ en 2009 , se observa en la Ilustración 4 que las edades de 20 a 44 años son las que presentan mayor frecuencia en ambos años. Sin embargo, en 2009 existe una ligera disminución en mujeres de 14 a los 39 años y se incrementa la participación en edades mayores a los 50 años.

Tabla 1. Población Económicamente Activa (PEA) y Población No Económicamente Activa (PNEA) por sexo (2007 y 2009) $)^{3}$

\begin{tabular}{|c|c|c|c|c|c|c|}
\hline & \multicolumn{3}{|c|}{2007} & \multicolumn{3}{|c|}{2009} \\
\hline & Hombre & Mujer & Total & Hombre & Mujer & Total \\
\hline PEA & $78.2 \%$ & $41.4 \%$ & $58.6 \%$ & $76.8 \%$ & $41.2 \%$ & $58.1 \%$ \\
\hline PNEA & $21.8 \%$ & $58.6 \%$ & $41.4 \%$ & $23.2 \%$ & $58.8 \%$ & $41.9 \%$ \\
\hline Total \% & $100 \%$ & $100 \%$ & $100 \%$ & $100 \%$ & $100 \%$ & $100 \%$ \\
\hline Total n & $35,460,057$ & $40,291,137$ & $75,751,194$ & $37,323,633$ & $41,394,701$ & $78,718,334$ \\
\hline
\end{tabular}

Ilustración 3. Características de la PEA femenina por grupos de edad (2007 y 2009) ${ }^{4}$

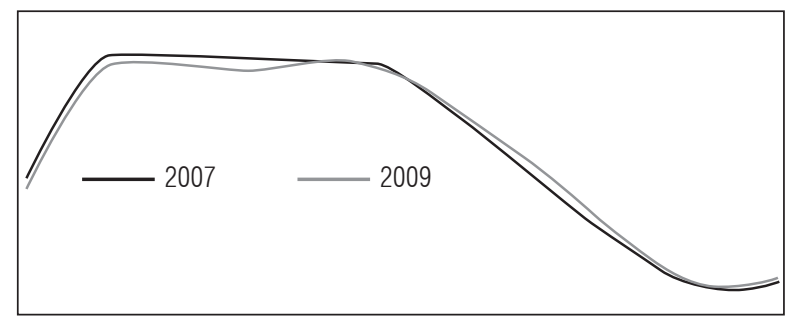

En el caso de los hombres, se muestra que la distribución de la PEA es semejante en 2007 y 2009. Sólo en el grupo de 30 a 34 disminuye la participación en el 2009, pero se compensa en el grupo de 50 a 54 años.
Ilustración 4. Características de la PEA masculina por grupos de edad (2007 y 2009) $)^{5}$

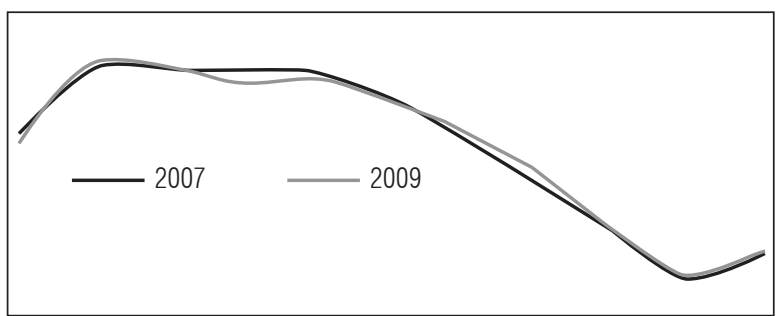

Es de notar, que los grupos de edad contemplan cinco años, pero el de 65 y más concentra sin restricción de edad a todas aquellas personas mayores de 65 años que reportaron estar económicamente activas. Esto se deriva de la definición propuesta por el INEGI donde señala que la población en edad

3 Fuente: Elaboración propia con base a los datos del segundo trimestre de 2007 y 2009 de la ENOE.

4 Fuente: Elaboración propia con base a los datos del segundo trimestre de 2007 y 2009 de la ENOE.

5 Fuente: Elaboración propia con base a los datos del segundo trimestre de 2007 y 2009 de la ENOE. 
laboral es "la población por arriba de una edad límite, después de la cual las personas pueden trabajar" (INEGI, 2009, 127). Esto quiere decir que hay un límite inferior, pero no superior, por lo que el incremento en el porcentaje del último grupo se debe por la acumulación de las personas mayores a 65 años, más que por el aumento de la participación económica de estas personas.

Dicha situación no permite obtener datos suficientes para corroborar lo mencionado por Salas (próxima publicación), donde señala que "el grupo de hombres de 60 y más años reduce su participación en la actividad económica, principalmente por la jubilación o pensión. Sin embargo, la crisis actual puede significar un aumento en las tasas de participación debido a la necesidad de contar con más ingresos para enfrentar la caída ya experimentada a partir de 2008" (Salas, s.f.).

En cuanto al estado civil (Tabla 2), puede verse que el porcentaje mayor de la PEA en 2007 y 2009 se encuentra entre los unidos para ambos sexos, seguido de los nunca unidos. En las diferencias por sexos se puede resaltar que de los unidos, los hombres de la PEA son quienes tienen el mayor porcentaje para ambos años, pero en la categoría de los nunca unidos, son las mujeres quienes están por encima de ellos.

Las categorías en que la PEA femenina registra porcentajes mayores en los niveles de instrucción son en la secundaria, así como el nivel medio superior y superior para ambos años. Sin embargo, se observa un ligero incremento de las mujeres que tienen el nivel medio superior y superior para el 2009 y una reducción de las aquellas que cuentan con primaria incompleta y primaria completa, es decir, podría afirmarse que las mujeres que forman parte de la PEA en 2009 tienen un nivel de instrucción mayor que el de las de 2007, puesto que una mayor proporción de ellas se ubica en el nivel más alto de instrucción.

La situación de los hombres es semejante a la de las mujeres, ya que disminuyó la proporción de hombres con primaria incompleta y completa del 2007 al 2009, pero el porcentaje mayor se localiza en aquellos que tienen secundaria completa, indicando que las mujeres económicamente activas cuentan con mayores niveles de instrucción que los hombres.

Tabla 2. Características de la PEA por estado civil y sexo (2007 y 2009) ${ }^{6}$

\begin{tabular}{|c|c|c|c|c|c|c|}
\hline & \multicolumn{3}{|c|}{2007} & \multicolumn{3}{|c|}{2009} \\
\hline & Hombre & Mujer & Total & Hombre & Mujer & Total \\
\hline \multicolumn{7}{|l|}{ Estado civil } \\
\hline Nunca unido & $28.3 \%$ & $35.4 \%$ & $31.0 \%$ & $28.6 \%$ & $35.1 \%$ & $31.0 \%$ \\
\hline Unido & $67.7 \%$ & $50.5 \%$ & $61.1 \%$ & $66.9 \%$ & $49.9 \%$ & $60.6 \%$ \\
\hline Alguna vez unido & $4.0 \%$ & $14.1 \%$ & $7.8 \%$ & $4.5 \%$ & $14.9 \%$ & $8.3 \%$ \\
\hline Total \% & $100 \%$ & $100 \%$ & $100 \%$ & $100 \%$ & $100 \%$ & $100 \%$ \\
\hline Total n & $27,726,245$ & $16,685,607$ & $44,411,852$ & $28,646,330$ & $17,062,025$ & $45,708,355$ \\
\hline
\end{tabular}

6 Fuente: Elaboración propia con base a los datos del segundo trimestre de 2007 y 2009 de la ENOE. 
Ilustración 5. Características de la PEA femenina por nivel de escolaridad (2007 y 2009)

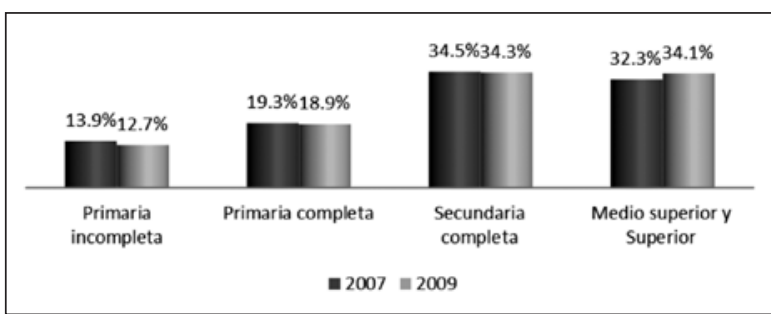

Ilustración 6. Características de la PEA masculina por nivel de escolaridad (2007 y 2009) ${ }^{8}$

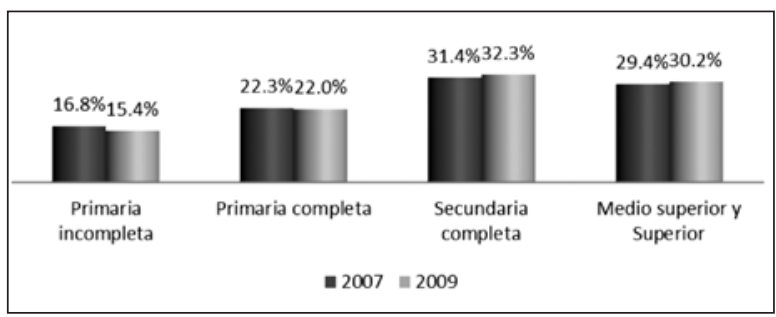

En resumen, al comparar las características sociodemográficas de la población nacional de 14 o más años de edad del 2007 y 2009 se encuentra lo siguiente. Los hombres siguen siendo quienes tienen mayor participación en actividades económicas, lo que ocurre con mayor frecuencia a edades más tempranas (14 a 19 años); una mayor proporción de los hombres unidos y nunca unidos son quienes se encuentran en la PEA y el nivel de instrucción predominante es secundaria completa. En cambio, la mayor proporción de las mujeres son económicamente inactivas; de las que sí están activas (41\%), las edades donde se concentran son entre los 20 y 49 años, pero en el 2009 aumentaron su participación las mayores de 50 años; un porcentaje importante de las unidas y nunca unidas son quienes realizan actividades económicas y tienen niveles de escolaridad mayores que los hombres, esto es, secundaria completa, media superior y superior.

La PEA se subdivide en población ocupada y desocupada, las cuales son definidas en siguientes apartados, en tanto se puede ver en el Tabla 3 que en 2007 el 96,6\% del total de la PEA se encontraba ocupada y el 3,4\% desocupada, para el 2009 disminuyó ligeramente la población ocupada al 94,8\% y la desocupada fue del 5,2\%. La reducción afectó tanto a mujeres como a hombres, pero es más evidente en estos últimos, puesto que la diferencia entre ambos años representa una desocupación de aproximadamente 600.000 hombres en 2009.

\subsection{Población ocupada}

La Comisión Económica para América Latina y el Caribe (CEPAL), define a los ocupados (o personas con empleo) como personas de 15 años y más que durante un breve periodo de referencia, como una semana o un día, estuvieron: i) con empleo asalariado, trabajando por un sueldo o salario, o con empleo pero sin trabajar por una ausencia temporal pero manteniendo un vínculo formal con su empleo, o ii) con empleo independiente, trabajando de forma independiente para obtener beneficios o ganancias familiares (incluye a los familiares no remunerados), o sin trabajar de forma independiente por ausencia temporal (CEPAL, 2008, 113).

Tabla 3. Clasificación de la PEA por condición de trabajo y sexo (2007 y 2009)10

\begin{tabular}{|c|c|c|c|c|c|c|}
\hline & \multicolumn{3}{|c|}{2007} & \multicolumn{3}{|c|}{2009} \\
\hline & Hombre & Mujer & Total & Hombre & Mujer & Total \\
\hline Ocupado & $96.80 \%$ & $96.30 \%$ & $96.60 \%$ & $94.60 \%$ & $95.20 \%$ & $94.80 \%$ \\
\hline Desocupado & $3.20 \%$ & $3.70 \%$ & $3.40 \%$ & $5.40 \%$ & $4.80 \%$ & $5.20 \%$ \\
\hline Total \% & $100.0 \%$ & $100.0 \%$ & $100.0 \%$ & $100.0 \%$ & $100.0 \%$ & $100.0 \%$ \\
\hline Total n & $27,726,245$ & $16,685,607$ & $44,411,852$ & $28,646,330$ & $17,062,025$ & $45,708,355$ \\
\hline
\end{tabular}

Fuente: Elaboración propia con base a los datos del segundo trimestre de 2007 y 2009 de la ENOE.

8 Fuente: Elaboración propia con base a los datos del segundo trimestre de 2007 y 2009 de la ENOE.

9 Fuente: Elaboración propia con base a los datos del segundo trimestre de 2007 y 2009 de la ENOE. 
El Instituto Nacional de Estadística, Geografía e Informática (INEGI), a su vez, considera a la población ocupada como todas las personas de determinada edad [en el caso de México es a partir de las 14 años] que en la semana de referencia: a) participaron en actividades económicas al menos una hora o un día a la semana a cambio de un ingreso monetario o en especie, o que lo hicieron sin recibir pago: b) no trabajaron pero cuentan con un empleo y; c) iniciarán alguna ocupación en el término de un mes o menos (INEGI 2009, 127).

La ENOE por ser una encuesta realizada por INEGI considera esta última concepción de población ocupada, además de que esta definición logra captar de mejor manera la condición de actividad y de ocupación. Esto se debe, entre otras cosas, a que cuenta con una definición operativa más acorde con la utilizada por la OCDE, dejando fuera de la ocupación a los iniciadores de un próximo trabajo; a los ocupados en ocupaciones marginales como la mendicidad disfrazada y a los ausentes temporales sin vínculo con la unidad empleadora (Junco, 2007, 29).

\subsubsection{Características sociodemográficas}

Los datos de la Tabla 5 señalan que la población ocupada de 2007 y 2009 se concentra en los adultos, seguida por los jóvenes y los porcentajes menores están en el grupo de 60 y más años, puesto que son las edades de retiro del mercado de trabajo. En los tres grupos se puede apreciar que no hubo cambios considerables entre los años de estudio, tanto en los totales como por sexo. La situación de los datos presentados en la Tabla 5 no evidencia lo mencionado por Salas (próxima publicación) donde dice que el grupo de hombres de 60 y más años reduce su participación en la actividad económica, principalmente por jubilación o pensión. Sin embargo, la crisis actual puede significar un aumento en las tasas de participación debido a la necesidad de contar con más ingresos para enfrentar la caída ya experimentada a partir de 2008 (Salas, s.f.).

Los porcentajes totales del grupo de 60 y más años de edad para ambos años es $8 \%$. Esto indica que no hubo un aumento en las tasas de participación como efecto de la crisis económica. Es importante señalar que Salas refiere al incremento de la participación de los hombres, pero con los datos comparativos de ambos años se puede ver que el crecimiento no se dio en los hombres sino en las mujeres, pero de manera moderada.

En cuanto al estado civil de la población ocupada, se puede ver que el mayor porcentaje es unida (más del $56 \%$ para 2007 y $61 \%$ en 2009). El grupo que le sigue es el de los nunca unidos y finalmente los que alguna vez estuvieron unidos. Es de notar que los hombres unidos aumentaron el porcentaje de ocupación en 2009 con respecto al 2007 y los solteros disminuyeron. La situación de las mujeres fue a la inversa, las unidas disminuyeron y las solteras incrementaron. Este efecto puede estar en relación con la crisis económica de 2008, donde el recorte de personal, como medida de flexibilidad numérica, afecta a las personas que son más costosas, como las mujeres unidas con hijos y en contraparte, se emplean a las mujeres solteras con condiciones más precarias.

En cuanto al nivel de instrucción que presenta la población ocupada se observa que los mayores porcentajes se encuentran en la primaria tanto para 2007 como 2009 (41,7\% y 38,7\% respectivamente), seguida por el nivel de secundaria y finalmente por el nivel medio superior y superior. En la Tabla 4 también se puede notar que existe una ligera disminución de la población ocupada con nivel de primaria, mientras que aumentaron los de nivel medio superior y superior de 2009 con referencia a 2007. Esta situación puede ser causada porque en la crisis económica quienes son afectados por recortes son quienes desempeñan actividades manuales o de baja calificación, lo que está más ligado a los bajos niveles de instrucción.

Las diferencias por sexo, muestran que los hombres ocupados tienen menores niveles de instrucción, en tanto, las mujeres son quienes tienen mejores niveles con porcentajes mayores en secundaria, medio superior y superior en comparación con los hombres, quienes tienen los porcentajes mayores en el nivel primaria. 
Tabla 4. Características de la población ocupada por sexo según grupos de edad, estado civil y nivel de instrucción $(2007 \text { y 2009) })^{10}$

\begin{tabular}{|c|c|c|c|c|c|c|}
\hline & \multicolumn{3}{|c|}{2007} & \multicolumn{3}{|c|}{2009} \\
\hline & Hombre & Mujer & Total & Hombre & Mujer & Total \\
\hline \multicolumn{7}{|l|}{ Grupos de edad } \\
\hline Jóvenes & $33.0 \%$ & $33.3 \%$ & $33.1 \%$ & $32.5 \%$ & $30.9 \%$ & $31.9 \%$ \\
\hline Adultos & $58.1 \%$ & $60.6 \%$ & $59.0 \%$ & $58.5 \%$ & $62.7 \%$ & $60.1 \%$ \\
\hline 60 y más & $8.9 \%$ & $6.1 \%$ & $7.9 \%$ & $9.0 \%$ & $6.3 \%$ & $8.0 \%$ \\
\hline Total \% & $100 \%$ & $100 \%$ & $100 \%$ & $100 \%$ & $100 \%$ & $100 \%$ \\
\hline Total n & $26,840,614$ & $16,066,042$ & $42,906,656$ & $27,100,150$ & $16,243,131$ & $43,343,281$ \\
\hline \multicolumn{7}{|l|}{ Estado civil } \\
\hline Nunca unido & $36.3 \%$ & $32.0 \%$ & $34.0 \%$ & $27.4 \%$ & $34.1 \%$ & $29.9 \%$ \\
\hline Unido & $59.0 \%$ & $55.0 \%$ & $56.9 \%$ & $68.2 \%$ & $50.8 \%$ & $61.6 \%$ \\
\hline Alguna vez unido & $4.7 \%$ & $13.0 \%$ & $9.1 \%$ & $4.5 \%$ & $15.2 \%$ & $8.5 \%$ \\
\hline Total \% & $100 \%$ & $100 \%$ & $100 \%$ & $100 \%$ & $100 \%$ & $100 \%$ \\
\hline Total n & $35,460,057$ & $40,291,137$ & $75,751,194$ & $27,100,150$ & $16,243,131$ & $43,343,281$ \\
\hline \multicolumn{7}{|l|}{ Nivel de instrucción } \\
\hline Primaria & $43.6 \%$ & $38.4 \%$ & $41.7 \%$ & $40.7 \%$ & $35.3 \%$ & $38.7 \%$ \\
\hline Secundaria & $30.6 \%$ & $33.6 \%$ & $31.8 \%$ & $31.8 \%$ & $33.9 \%$ & $32.6 \%$ \\
\hline $\begin{array}{l}\text { Medio superior } \\
\text { y Superior }\end{array}$ & $25.7 \%$ & $27.9 \%$ & $26.5 \%$ & $27.4 \%$ & $30.7 \%$ & $28.6 \%$ \\
\hline Total \% & $100 \%$ & $100 \%$ & $100 \%$ & $100 \%$ & $100 \%$ & $100 \%$ \\
\hline Total n & $26,840,614$ & $16,066,042$ & $42,906,656$ & $27,100,150$ & $16,243,131$ & $43,343,281$ \\
\hline
\end{tabular}

\subsubsection{Características laborales}

De los 42.906 .656 ocupados, más de 17 millones se encuentran en la rama de actividad de servicios lo que provoca que la actividad predominante del país sea éste, seguida por el comercio, la industria manufacturera y el agropecuario para 2007 y 2009. Las mujeres se ocupan primordialmente en la rama de actividad de servicios, seguida por el comercio y la industria manufacturera, con un ligero aumento en servicios para el 2009 (de $50,1 \%$ a $52,8 \%$ ) y una disminución en la industria (de 16,8\% a 14,9\%) en comparación con 2007.

La mayor proporción de los hombres ocupados, al igual que las mujeres, se encuentra en la rama de actividad de servicios (34,4\% y 36,1\% en cada año); el comercio, industria manufacturera, actividades agropecuarias y de construcción, las que cuentan con participaciones equivalentes (15\%, 15\%, 18\% y $12 \%$ respectivamente) y al sumarlas representan más del 60\% para ambos años.

Para entender mejor la distribución por rama de actividad tanto de hombres como de mujeres es importante mencionar que la industria manufacturera tuvo un declive en el 2009 en comparación con el 2007. García (2010) señala que sobresale el descenso continuo de las actividades agrícolas y la baja moderada en la fuerza de trabajo en el sector secundario (industria extractiva, manufacturera y la construcción) en la primera década del siglo XXI. En años recientes dicha actividad [industria maquiladora] se ha visto seriamente afectada por los altibajos de la economía estadounidense y la competencia con China (García, 2010, 81).

10 Fuente: Elaboración propia con base a los datos del segundo trimestre de 2007 y 2009 de la ENOE. 
Al observar la distribución de la población ocupada por sector de actividad puede apreciarse que la población ocupada a nivel nacional se encuentra concentrada en el sector terciario, pero es predominante en el caso de las mujeres, donde se tiene el 77,1\% en el 2007 y $80 \%$ en el 2009. Este aumento se corresponde con una disminución en el porcentaje de los otros dos sectores de actividad, donde se nota que el sector primario baja del 4,4\% al 3,4\%. La situación de los hombres es semejante, ya que también existe un descenso importante en el sector secundario y un incremento en el tercia- rio. Esta distribución por sector está acorde con lo indicado por la bibliografía especializada. ${ }^{11}$

En cuanto tamaño de establecimiento, se observa en la Tabla 5 que tanto para el 2007 como 2009, la categoría de micro establecimiento es la que tiene el mayor porcentaje $(54,5 \%$ y $54,6 \%$ respectivamente). Esta distribución es consistente con la encontrada previamente en la bibliografía especializada. Salas (s.f.) indica que la polarización por tamaño de establecimiento, continúa, y además se reafirma la importancia de las microunidades como generadoras de empleo.

Tabla 5. Características de la población ocupada por sexo según rama, sector de actividad y tamaño de establecimiento $(2007 \text { y 2009) })^{12}$

\begin{tabular}{|c|c|c|c|c|c|c|}
\hline & \multicolumn{3}{|c|}{2007} & \multicolumn{3}{|c|}{2009} \\
\hline & Hombre & Mujer & Total & Hombre & Mujer & Total \\
\hline \multicolumn{7}{|l|}{ Rama de actividad } \\
\hline Construcción & $12.9 \%$ & $.7 \%$ & $8.4 \%$ & $12.6 \%$ & $.7 \%$ & $8.1 \%$ \\
\hline Industria manufacturera & $16.2 \%$ & $16.8 \%$ & $16.4 \%$ & $15.0 \%$ & $14.9 \%$ & $14.9 \%$ \\
\hline Comercio & $15.5 \%$ & $27.0 \%$ & $19.8 \%$ & $15.5 \%$ & $27.2 \%$ & $19.9 \%$ \\
\hline Servicios & $34.4 \%$ & $50.1 \%$ & $40.3 \%$ & $36.1 \%$ & $52.8 \%$ & $42.3 \%$ \\
\hline Agropecuario & $18.9 \%$ & $4.4 \%$ & $13.5 \%$ & $18.8 \%$ & $3.4 \%$ & $13.0 \%$ \\
\hline Total \% & $100 \%$ & $100 \%$ & $100 \%$ & $100 \%$ & $100 \%$ & $100 \%$ \\
\hline Total n & $26,840,614$ & $16,066,042$ & $42,906,656$ & $27,100,150$ & $16,243,131$ & $43,343,281$ \\
\hline \multicolumn{7}{|l|}{ Sector de actividad } \\
\hline Primario & $18.9 \%$ & $4.4 \%$ & $13.5 \%$ & $18.8 \%$ & $3.4 \%$ & $13.0 \%$ \\
\hline Secundario & $30.4 \%$ & $17.9 \%$ & $25.7 \%$ & $28.9 \%$ & $16.0 \%$ & $24.0 \%$ \\
\hline Terciario & $49.9 \%$ & $77.1 \%$ & $60.1 \%$ & $51.6 \%$ & $80.0 \%$ & $62.2 \%$ \\
\hline Total \% & $100 \%$ & $100 \%$ & $100 \%$ & $100 \%$ & $100 \%$ & $100 \%$ \\
\hline Total n & $26,840,614$ & $16,066,042$ & $42,906,656$ & $27,100,150$ & $16,243,131$ & $43,343,281$ \\
\hline \multicolumn{7}{|l|}{ Tamaño de establecimiento } \\
\hline Micro & $53.5 \%$ & $56.1 \%$ & $54.5 \%$ & $54.0 \%$ & $55.7 \%$ & $54.6 \%$ \\
\hline Pequeña & $11.2 \%$ & $9.8 \%$ & $10.7 \%$ & $11.1 \%$ & $10.0 \%$ & $10.7 \%$ \\
\hline Mediana & $10.9 \%$ & $10.9 \%$ & $10.9 \%$ & $10.3 \%$ & $11.4 \%$ & $10.7 \%$ \\
\hline Grande & $22.5 \%$ & $22.0 \%$ & $22.3 \%$ & $21.7 \%$ & $20.9 \%$ & $21.4 \%$ \\
\hline Total \% & $100 \%$ & $100 \%$ & $100 \%$ & $100 \%$ & $100 \%$ & $100 \%$ \\
\hline Total n & $26,840,614$ & $16,066,042$ & $42,906,656$ & $27,100,150$ & $16,243,131$ & $43,343,281$ \\
\hline
\end{tabular}

11 La terciarización de la economía y de la fuerza de trabajo mexicana forma parte de una tendencia internacional en este sentido, pues se requiere cada vez menos mano de obra para producir los alimentos y los productos manufacturados que consumimos (García, 2010, 81).

12 Fuente: Elaboración propia con base a los datos del segundo trimestre del 2007 y 2009 de la ENOE. 
El grupo de ocupación predominante para 2007 y 2009 es el manual (58,9\% y 57,6\% respectivamente). Sin embargo se observa que el peso del porcentaje se deriva de los hombres, puesto que más del $66 \%$ de los hombres ocupados se encuentran como manuales, mientras que más del 56\% de los no manuales para ambos años, son mujeres.

La mayoría de la población ocupada nacional es trabajadora subordinada y remunerada en ambos años con porcentajes mayores a $65 \%$, lo que significa que más de 27 millones de personas se encuentran en dicha categoría. Los trabajadores por cuenta propia ocupan la segunda posición con más del 22\%. También es de notar que los trabajadores no remunerados representan un 6,8\% en el 2007 y $6,5 \%$ en el 2009 , porcentajes que disminuyeron en comparación con los datos citados por Muños (2008), donde este mismo grupo ocupaba un 7,4\% en el 2005 y $7 \%$ en el 2006.
En cuanto a los niveles de ingresos, la categoría que tiene mayor proporción es la de más de uno hasta tres salarios mínimos diarios para 2007 y 2009, seguida por quienes reciben más de tres salaros mínimos, donde uno de cada tres ocupados se encuentra en tal categoría. En cuanto a las diferencias por sexo se observa que, tanto hombres como mujeres, la categoría de más alto porcentaje es la de más de uno hasta tres salarios mínimos, sin embargo, el segundo porcentaje más alto en los hombres es el de más de tres salaros mínimos, mientras que las mujeres es hasta un salario mínimo. Estos datos reflejan que la situación laboral de las mujeres no es semejante a la de los hombres, ya que en datos anteriores se observa que son ellos quienes tienen menor escolaridad y ocupan puestos manuales, pero reciben mayores ingresos, en tanto que las mujeres tienen mayor escolaridad y se desempeñan en su mayoría como no manuales pero reciben menores ingresos.

Tabla 6. Características de la población ocupada por sexo según grandes grupos de ocupación y posición en el trabajo $(2007 \text { y 2009) })^{13}$

\begin{tabular}{|c|c|c|c|c|c|c|}
\hline & \multicolumn{3}{|c|}{2007} & \multicolumn{3}{|c|}{2009} \\
\hline & Hombre & Mujer & Total & Hombre & Mujer & Total \\
\hline \multicolumn{7}{|l|}{ Grupos ocupacionales } \\
\hline Manual & $67.8 \%$ & $43.9 \%$ & $58.9 \%$ & $66.8 \%$ & $42.2 \%$ & $57.6 \%$ \\
\hline No manual & $32.2 \%$ & $56.1 \%$ & $41.1 \%$ & $33.1 \%$ & $57.7 \%$ & $42.4 \%$ \\
\hline Total \% & $100.0 \%$ & $100.0 \%$ & $100.0 \%$ & $100.0 \%$ & $100.0 \%$ & $100.0 \%$ \\
\hline Total n & $26,840,614$ & $16,066,042$ & $42,906,656$ & $27,100,150$ & $16,243,131$ & $43,343,281$ \\
\hline \multicolumn{7}{|l|}{ Posición en el trabajo } \\
\hline Trab. subord y remun. & $65.7 \%$ & $65.1 \%$ & $65.5 \%$ & $66.5 \%$ & $65.4 \%$ & $66.1 \%$ \\
\hline Empleadores & $6.5 \%$ & $2.5 \%$ & $5.0 \%$ & $5.8 \%$ & $2.3 \%$ & $4.5 \%$ \\
\hline Trab. cta propia & $22.8 \%$ & $22.3 \%$ & $22.6 \%$ & $22.9 \%$ & $23.1 \%$ & $23.0 \%$ \\
\hline Trab. no remun. & $4.9 \%$ & $10.0 \%$ & $6.8 \%$ & $4.8 \%$ & $9.2 \%$ & $6.5 \%$ \\
\hline Total \% & $100.0 \%$ & $100.0 \%$ & $100.0 \%$ & $100.0 \%$ & $100.0 \%$ & $100.0 \%$ \\
\hline Total n & $26,840,614$ & $16,066,042$ & $42,906,656$ & $27,100,150$ & $16,243,131$ & $43,343,281$ \\
\hline
\end{tabular}

En cuanto a la calidad del empleo Salas indica que, la calidad del trabajo está fuertemente asociada a la existencia de prestaciones laborales y de seguridad social, lo que expresa que el trabajador está realmente protegido por la legislación laboral. Las pres- taciones laborales incluyen el pago de vacaciones, de aguinaldo, reparto de utilidades, mientras que las prestaciones de seguridad social se refieren tanto al acceso a servicios médicos, como a la seguridad social en sí misma (Salas, s.f.).

13 Fuente: Elaboración propia con base a los datos del segundo trimestre de 2007 y 2009 de la ENOE. 
Con esta información se puede señalar (Tabla 7) que aproximadamente 25 millones de ocupados no cuentan con prestaciones de ningún tipo, mientras que el $41 \%$ restante tiene prestaciones, esto es, cuatro de cada diez ocupados cuentan con una protección por la legislación laboral.

En cuanto a la variable de condición de acceso a instituciones de salud, los datos indican que más 27 millones de ocupados en México no cuentan con acceso a institución de salud tanto en 2007 como 2009. Esta situación implica que deja en un estado de vulnerabilidad a los trabajadores y a sus dependientes en caso de enfermedad o accidente, aún aquellos que son derivados de la propia actividad laboral.

A manera de resumen de esta apartado se indica que, la población ocupada de México para 2007 y
2009 se encuentra concentrada en los adultos; son unidos en su mayoría; tienen secundaria completa principalmente; se ubican en actividades de la rama de servicios y del sector terciario; son manuales, trabajadores subordinados y remunerados con niveles de ingreso entre uno hasta tres salarios mínimos y se emplean en microempresas; finalmente, más de la mitad de la población ocupada no tiene prestaciones ni acceso a instituciones de salud.

La información anterior corrobora que las condiciones laborales de la mayoría de la población ocupada del país son precarias, por lo que "está altamente correlacionada con la informalidad y el empleo en sectores de baja productividad que por lo general, es de mala calidad y se caracteriza por la inestabilidad laboral, bajas remuneraciones y la falta de acceso a seguridad social" (CEPAL, 2008, 108).

Tabla 7. Características de la población ocupada por sexo según nivel de ingreso, prestaciones y condición de acceso a instituciones de salud (2007 y 2009) ${ }^{14}$

\begin{tabular}{|c|c|c|c|c|c|c|}
\hline & \multicolumn{3}{|c|}{2007} & \multicolumn{3}{|c|}{2009} \\
\hline & Hombre & Mujer & Total & Hombre & Mujer & Total \\
\hline \multicolumn{7}{|l|}{ Nivel de ingreso } \\
\hline Hasta $1 \mathrm{sm}$ & $17.1 \%$ & $27.7 \%$ & $21.1 \%$ & $17.7 \%$ & $27.3 \%$ & $21.3 \%$ \\
\hline Más de 1 hasta $3 \mathrm{sm}$ & $41.2 \%$ & $44.2 \%$ & $42.3 \%$ & $41.4 \%$ & $42.9 \%$ & $42.0 \%$ \\
\hline Más de 3 m & $35.3 \%$ & $22.6 \%$ & $30.5 \%$ & $32.1 \%$ & $22.3 \%$ & $28.4 \%$ \\
\hline Total \% & $100 \%$ & $100 \%$ & $100 \%$ & $100 \%$ & $100 \%$ & $100 \%$ \\
\hline Total n & $26,840,614$ & $16,066,042$ & $42,906,656$ & $27,100,150$ & $16,243,131$ & $43,343,281$ \\
\hline \multicolumn{7}{|l|}{ Prestaciones } \\
\hline Sin prestaciones & $59.4 \%$ & $56.0 \%$ & $58.1 \%$ & $59.0 \%$ & $55.5 \%$ & $57.7 \%$ \\
\hline Con prestaciones & $40.3 \%$ & $43.7 \%$ & $41.6 \%$ & $40.3 \%$ & $44.0 \%$ & $41.7 \%$ \\
\hline Total \% & $100 \%$ & $100 \%$ & $100 \%$ & $100 \%$ & $100 \%$ & $100 \%$ \\
\hline Total n & $26,840,614$ & $16,066,042$ & $42,906,656$ & $27,100,150$ & $16,243,131$ & $43,343,281$ \\
\hline \multicolumn{7}{|c|}{ Condición de acceso a instituciones de salud } \\
\hline Con acceso & $35.7 \%$ & $36.9 \%$ & $36.1 \%$ & $34.9 \%$ & $36.6 \%$ & $35.5 \%$ \\
\hline Sin acceso & $63.7 \%$ & $62.6 \%$ & $63.3 \%$ & $64.5 \%$ & $62.9 \%$ & $63.9 \%$ \\
\hline Total \% & $100 \%$ & $100 \%$ & $100 \%$ & $100 \%$ & $100 \%$ & $100 \%$ \\
\hline Total n & $26,840,614$ & $16,066,042$ & $42,906,656$ & $27,100,150$ & $16,243,131$ & $43,343,281$ \\
\hline
\end{tabular}

14 Fuente: Elaboración propia con base a los datos del segundo trimestre de 2007 y 2009 de la ENOE. 


\subsection{Trabajadores subordinados y remunerados por modalidad de contratación}

Los trabajadores subordinados y remunerados son aquellos que tienen un jefe o superior y reciben un pago ${ }^{15}$. En México para 2007 y 2009 son aproximadamente 28 millones, de los cuales el 52\% cuenta con contrato escrito, siendo las mujeres quienes tienen el mayor porcentaje en ambos años, incrementándose para el 2009, en tanto, los hombres tienen un porcentaje del $49 \%$ de no contar con contrato en 2007 y 2009. Estos datos coinciden con la información proporcionada por García (2010) donde indica que la proporción de las mujeres ocupadas con contrato escrito es mayor que la de los hombres, con lo cual no se puede sostener que el trabajo femenino esté en peores condiciones que la de los hombres en cuanto a lo que implica contar con una relación contractual formal, esto es, protegido y con prestaciones.

En este apartado se analizan las condiciones de los trabajadores asalariados que cuentan con contrato y quienes carecen de él, tanto en 2007 como en 2009 , con la intención de conocer si la crisis económica iniciada en 2008 tuvo repercusiones en este grupo. Como antecedente, Salas (s.f.) indica que "las condiciones de acceso a la protección social y existencia de contratos, no parecen haberse deteriorado visiblemente en este periodo [1995 y 2009]". Esta situación que es visible en el caso de los contratos, ya que no se muestra diferencia alguna en el comparativo. Sin embargo, en el acceso a prestaciones y al acceso a instituciones de salud, sí existe una variación.

\subsubsection{Características sociodemográficas}

En la Tabla 8 se observa que los trabajadores subordinados y remunerados de 2007 y 2009 que cuentan con contrato por escrito son adultos, el estado civil predominante es unido y el nivel de instrucción es medio superior y superior. En tanto, quienes no tienen contrato escrito son jóvenes y adultos, unidos y solteros y la escolaridad es primaria.

Un aspecto a resaltar es, de los más de 13 millones de trabajadores subordinados y remunerados que no cuentan con contrato escrito en 2007, 8.648.487 son hombres, mientras que el resto son mujeres. En 2009 los datos se mantienen similares. Tal situación converge con la información presentada por Muños (2008) y García (2010), donde señalan que la fuerza de trabajo femenina no se encuentra en peores circunstancias en comparación con los hombres en cuanto a la existencia de contratos escritos.

Otro punto a resaltar en cuanto al estado civil de los trabajadores subordinados hombres con contrato y sin él, es que son mayoritariamente unidos (seis de cada diez), a diferencia de las mujeres que tienen porcentajes similares las unidas y solteras, dicho de otra forma, de diez mujeres asalariadas con contratos, cuatro son solteras, cuatro unidas y dos alguna vez estuvieron unidas, manteniendo resultados similares las mujeres sin contrato escrito. Finalmente, los datos referentes al nivel de instrucción coinciden con la bibliografía especializada (Muños, 2008; García, 2010), donde se indica que aquellos que carecen de contratos escritos, cuentan con menor escolaridad, puesto que más del 50\% de este grupo, tanto hombres como mujeres, tienen el nivel de primaria.

\subsubsection{Características laborales}

En la información presentada (Anexo), se observa que los trabajadores subordinados y remunerados con contrato escrito tienen ingresos mayores a los tres salarios mínimos diarios, están ocupados en actividades no manuales, en la rama de servicios y por ende en el sector terciario ${ }^{16}$ y el tamaño del establecimiento al que pertenecen son los grandes. García $(2010,84)$ señala que "se trata en todos los casos de actividades económicas usualmente ejercidas bajo condiciones formales de contratación".

15 También se les denomina trabajadores asalariados.

16 Hay que señalar que los datos del sector terciario, ejerce un efecto estructural, ya que como se mencionó anteriormente, más del $60 \%$ de la población ocupada se encuentra laborando en dicho sector. 
Por su parte, los trabajadores subordinados y remunerados que no tienen contrato escrito cuentan con ingresos que van de uno hasta tres salarios mínimos diarios, el grupo de ocupación es manual, la rama y sector de actividad es terciario y son micro los establecimientos donde laboran.

Los resultados no difieren de estudios previos (Muños, 2008; García, 2010), pero es verdad que surge una preocupación, este panorama no es muy alentador, puesto que la mitad de la población asalariada no tiene un contrato escrito. Esto significa a grandes rasgos una baja presencia de prestaciones entre los asalariados subordinados y por consiguiente un panorama de inestabilidad laboral en lo que a seguridad en el empleo se refiere (Muños, 2008, 33).

Adicional a la seguridad en el empleo que menciona Muños, los datos presentados, evidencian que las condiciones de quienes no cuentan con contrato escrito son más precarias como el tener menores ingresos en comparación con aquellos que sí cuentan con él. Además, el grupo de personas con dicha situación contractual, está empleado en establecimientos micro, lo que manifiesta un importante sector que está en la informalidad.

\subsection{Trabajadores subordinados y remunerados por tipo de contrato escrito}

En cuanto a la tipología de los contratos en México, Reynoso (1997) señala que la Ley Federal de Trabajo reconoce la posible existencia de cuatro modalidades contractuales expresas en materia de duración. Las modalidades expresas son aquéllas en las cuales se ha celebrado un acto jurídico, en este caso un contrato de trabajo, en el cual, como el nombre lo indica, de manera expresa se ha señalado el tipo de duración a que han de sujetarse las partes, estas modalidades son: por tiempo indeterminado, por tiempo determinado, por obra determinada y por inversión de capital determinado. (Reynoso, 1997, 82).

El INEGI (2007) a través de la ENOE, distingue en dos grupos el tipo de contrato: i) base, planta o por tiempo indefinido $y$, ii) temporal u obra determinada. Siendo así, se deja fuera el contrato por inversión de capital determinado que menciona Reynoso
(1997) pero que en la práctica tiene escasa o nula presencia en la realidad laboral mexicana, salvo en actividades de explotación en la minería.

De los que declararon contar con contrato escrito, el $82,5 \%$ y 83,3\% para 2007 y 2009 respectivamente, son de base, planta o tiempo indefinido, mientras que el $17,2 \%$ y $16,1 \%$ restante, son temporales o por obra determinada, lo que corroboraría el supuesto legal de que los contratos indefinidos son la regla. En los datos del Tabla 12 se observa que hubo una ligera disminución de los contratos temporales pasando de 2.516.057 en 2007 a 2.429.481 en 2009 , lo que resulta coherente con el menor costo que supone prescindir de este tipo de trabajadores. En el caso de los de contrato de tiempo indeterminado se muestra que hubo un aumento de casi medio millón de personas con dicho contrato, pasando de los 12.058.356 en el primer año a 12.546.458 en 2009. Esta información no es consistente con los datos mostrados sobre las prestaciones de los ocupados, pero para cotejar la información, sería necesario profundizar en las cláusulas de los contratos o en arreglos que se manifiestan como repercusiones de la flexibilización laboral, lo cual no es el objetivo del presente trabajo.

\subsubsection{Características sociodemográficas}

Los trabajadores subordinados y remunerados que cuentan con contrato de tiempo definido tienen distribuciones similares entre los jóvenes y adultos, los que son unidos y solteros $y$, quienes tienen secundaria y media superior para 2007 y 2009. En tanto, quienes tienen contrato por tiempo indeterminado son en su mayoría adultos, están unidos y el nivel de instrucción es medio superior y superior.

En los datos también se observa que incrementaron los contratos de base, planta o tiempo indefinido en 2009 con respecto a 2007 en la fuerza de trabajo femenina. En el caso de los hombres, no se nota tal incremento. Este hecho contrasta con lo mencionado por la CEPAL (2008), donde se señala que la importancia de los contratos de tiempo indefinido disminuye cada vez más, afectando principalmente a las mujeres y a los nuevos entrantes al mercado de trabajo. 
Un dato a resaltar y que también es señalado por García (2010) es que la importancia de los trabajadores con contratos temporales se incrementa al aumentar el nivel de instrucción, puesto que de cada cien trabajadores con contrato temporal, 20 tienen la primaria, 38 secundaria y 42 cuentan con niveles de instrucción de medio superior y superior. La situación anterior estaría sugiriendo dos escenarios. Por un lado que la posible precariedad generada por los contratos temporales, estaría en los más calificados. Por otro lado, podría ser el efecto de la naturaleza del trabajo desempeñado como la elaboración de proyectos especiales, consultorías, entre otros.

\subsubsection{Características laborales}

Los trabajadores que cuentan con contrato temporal tienen ingresos en su mayoría de entre uno hasta tres salarios mínimos diarios, tienen una distribución semejante entre manuales y no manuales, desempeñan actividades en la rama de servicios, en el sector terciario y el tamaño de establecimiento es grande. Un beneficio de las personas que cuentan con contrato de base es en el nivel de ingreso, donde se observa que más de la mitad de este grupo recibe más de tres salarios mínimos diarios. García señala, "es indiscutible que ser trabajador temporal implica tener un ingreso menor que el que se obtiene al ser trabajador permanente; asimismo, los temporales sólo perciben ingresos ligeramente superiores a aquellos que no tienen contrato alguno (García, 2010, 97).

La información del Anexo estaría evidenciando que aún dentro del sector formal y de los establecimientos grandes, el contrato temporal tiene gran peso y que se está haciendo uso de él sin respetar los tres casos especiales que menciona la Ley Federal del Trabajo (2010) ya anteriormente citados.

\section{Conclusiones}

La situación del mercado laboral que actualmente se presenta en México, es derivado de un conjunto de circunstancias que están entrelazadas como las presiones económicas externas, la vigencia de las regulaciones, la presencia de los sindicatos, las estrategias de políticas públicas, los convenios con otros países, la participación del sector privado, por mencionar algunos. Sin embargo, es cada vez más evidente las transformaciones que existen en dicho mercado y, para llevar a cabo políticas públicas planificadas con objetivos a corto, mediano y largo plazo es necesario conocer el fenómeno. Por ello, el presente artículo mostró desde una perspectiva socio-demográfica las condiciones de los trabajadores con empleos estables para evidenciar el impacto que tiene una regulación rígida ante catalizadores de cambio como la crisis económica de 2008.

Entre los resultados obtenidos del análisis cuantitativo se observa que las condiciones sociodemográficas de la Población Económicamente Activa de 2009 no presentan cambios importantes con respecto a las de 2007. Esto demuestra, de manera general, que la crisis económica iniciada en 2008 no impactó de forma sustancial en la estructura de la PEA mexicana. La PEA disminuyó y la PNEA aumentó, aunque no significativamente $(41,3 \%$ a 41,9\%). De igual manera, la población ocupada no aumenta en 2009, lo que podría indicar que no se generaron o se redujeron espacios en el mercado laboral.

La evidencia indica que entre los afectados, ya sea por crisis o por cuestiones de ajuste del mercado laboral fueron: las mujeres, los jóvenes y mayores de 60 años, los solteros, quienes tienen menor escolaridad, los que desempeñan actividades manuales y principalmente a aquellos de la industria manufacturera y del sector secundario.

En cuestión de contratos, resulta interesante observar que, de manera contraria a lo esperado, hubo un incremento en el grupo de las mujeres ocupadas con contrato y principalmente de tiempo indefinido en 2009 en comparación con 2007, beneficiando especialmente a las adultas, a las más escolarizadas, a quienes desempeñan actividades no manuales y están insertas en el sector terciario. 
La reducción de prestaciones y de ingresos de la población ocupada de 2009 con respecto a la de 2007, logran ser aspectos de mayor afectación, que podrían ser resultado de ajustes derivado de la crisis económica de 2008, esto es, no se pierde el trabajo, pero sí se disminuyen prestaciones o ingresos.

Finalmente, los datos muestran que las mujeres tienen condiciones más desfavorables que los hombres, puesto que desempeñan actividades laborales similares, tienen mayor nivel de instrucción, cuentan con contratos escritos de tiempo indefinido, pero sus ingresos y las prestaciones son menores.

Con las evidencias anteriores, se puede concluir que la ley que está vigente en México, catalogada como rígida, protegió a los trabajadores estables de perder su empleo después de la crisis económica de 2008, aunque se disminuyeron las prestaciones e ingresos. Sin embargo, el estudio deja varias puertas abiertas para futuros análisis como las cargas económicas que soportaron los empleadores y si esto es fuente de presiones para flexibilizar el mercado laboral. Por otro lado, ¿cuáles fueron las repercusiones en los trabajadores flexibles o fuera de la cobertura legal con la crisis económica de 2008? Finalmente, ¿cuáles son las estrategias en los hechos por parte de los trabajadores estables, los flexibles y los empleadores ante una crisis económica y la presencia de una ley rígida para mantenerse en el mercado laboral?

\section{Referencias}

BID (2004). Se buscan buenos empleos: los mercados laborales en América Latina. Washington: Banco Interamericano de Desarrollo.

Bensusán, G. (2006). "Diseño legal y desempeño real: México". En: Bensusán, G. Diseño legal y desempeño real: instituciones laborales en América Latina. México: Universidad Autónoma Metropolitana.

CEPAL (2008). Panorama Social de América Latina 2008. Naciones Unidas, División de Desarrollo Social y la División de Estadística y proyecciones Económicas de la CEPAL. Santiago de Chile: Publicaciones de las Naciones Unidas.

De la Garza y Toledo, E. (coord.) (2011a). Trabajo no clásico, organización y acción colectiva, Vol. I, México: UAM-I.

De la Garza y Toledo, E. (coord.) (2011b). Trabajo no clásico, organización y acción colectiva, Vol. II, México: UAM-I.

García, B. (2010). "Inestabilidad laboral en México: el caso de los contratos de trabajo". En: Estudios Demollustración y Urbanos, 25 (1), enero-abril 2010. México: Colegio de México / CEDUA.

INEGI (2007). Encuesta Nacional de Ocupación y Empleo 2007. Aguascalientes: Instituto Nacional de Estadística y Geografía.

INEGI (2009). Estadísticas de la dinámica laboral en México 2005-2007. Aguascalientes: Instituto Nacional de Estadística y Geografía.

Junco, J. (2007). Trayectorias laborales discontinuas y rotación laboral en México: causas y consecuencias. Tesis para optar al grado de Maestro en Políticas Públicas Comparadas. México: FLACSO.

Muños, J. (2008). Un acercamiento a la inestabilidad laboral de los trabajadores asalariados. Estimación a partir del segundo trimestre de la ENOE, 2006. Tesis para optar al grado de Maestro en Demografía. México: Colegio de México.

Reynoso, C. (1997). Permanencia de las relaciones de trabajo. México: UAM-Azcapotzalco.

Salas, C. (s.f.). Ocupación, desocupación, ingresos y condiciones de trabajo en México. México: Colegio de Tlaxcala / IET. 


\section{ANEXO}

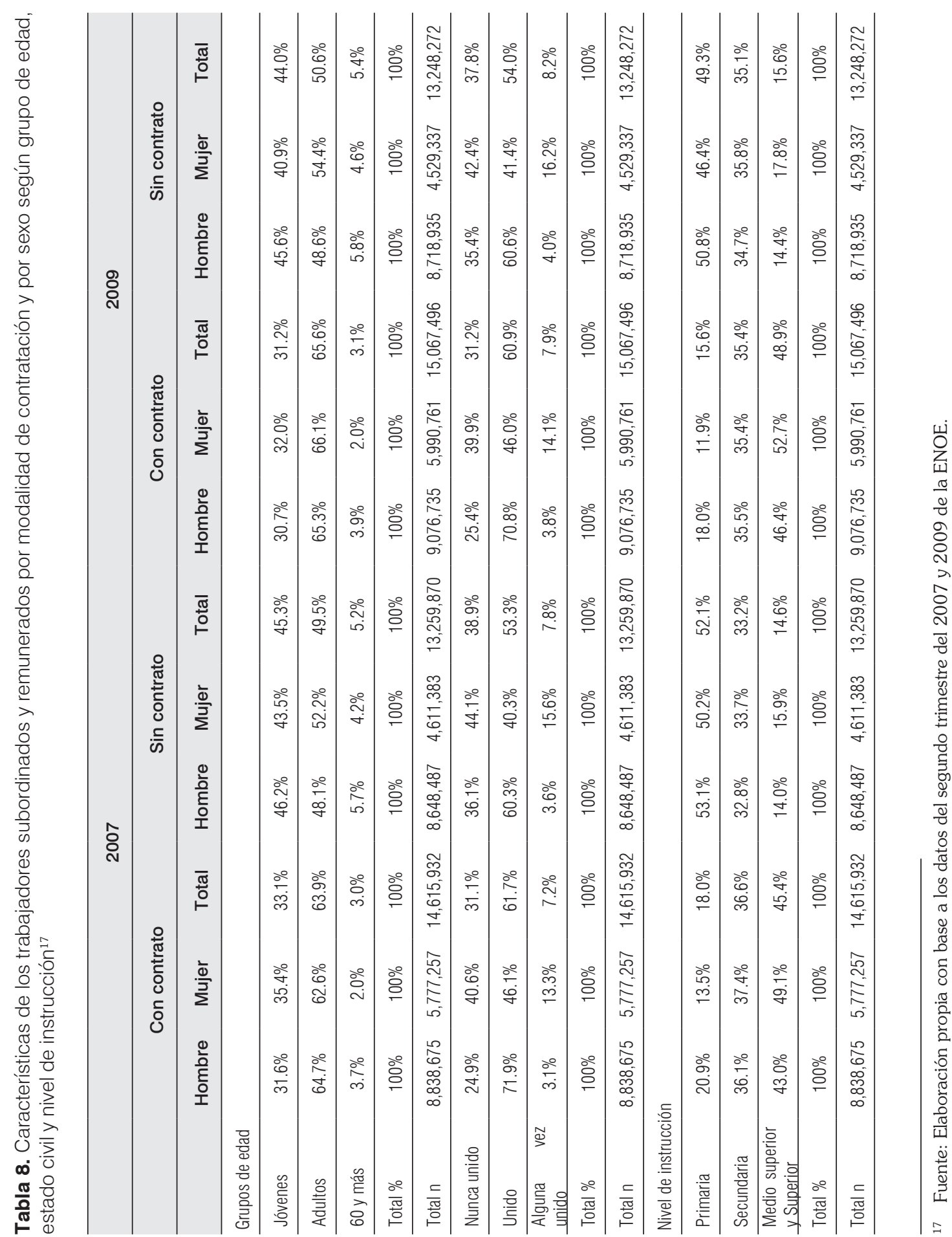




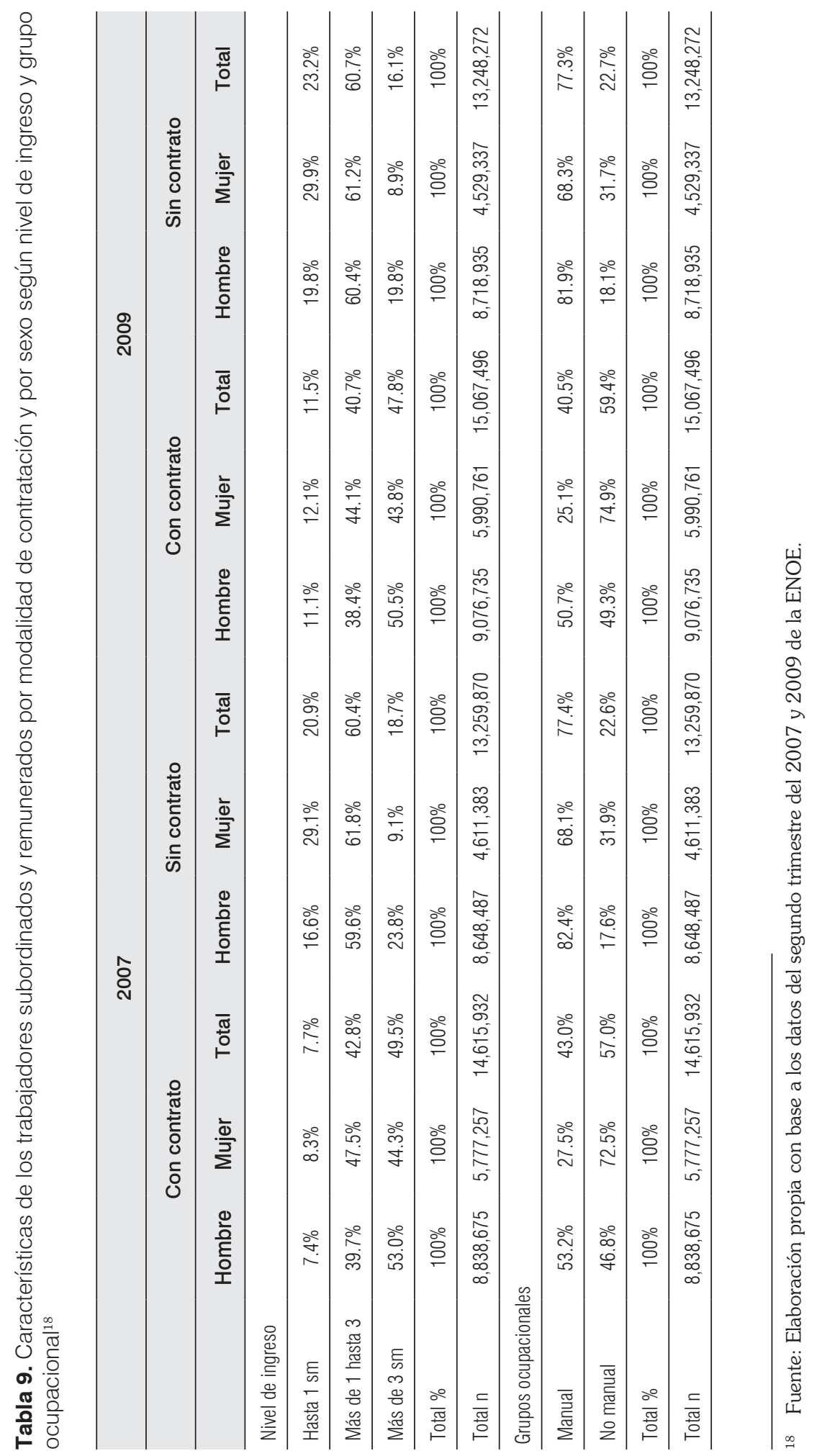




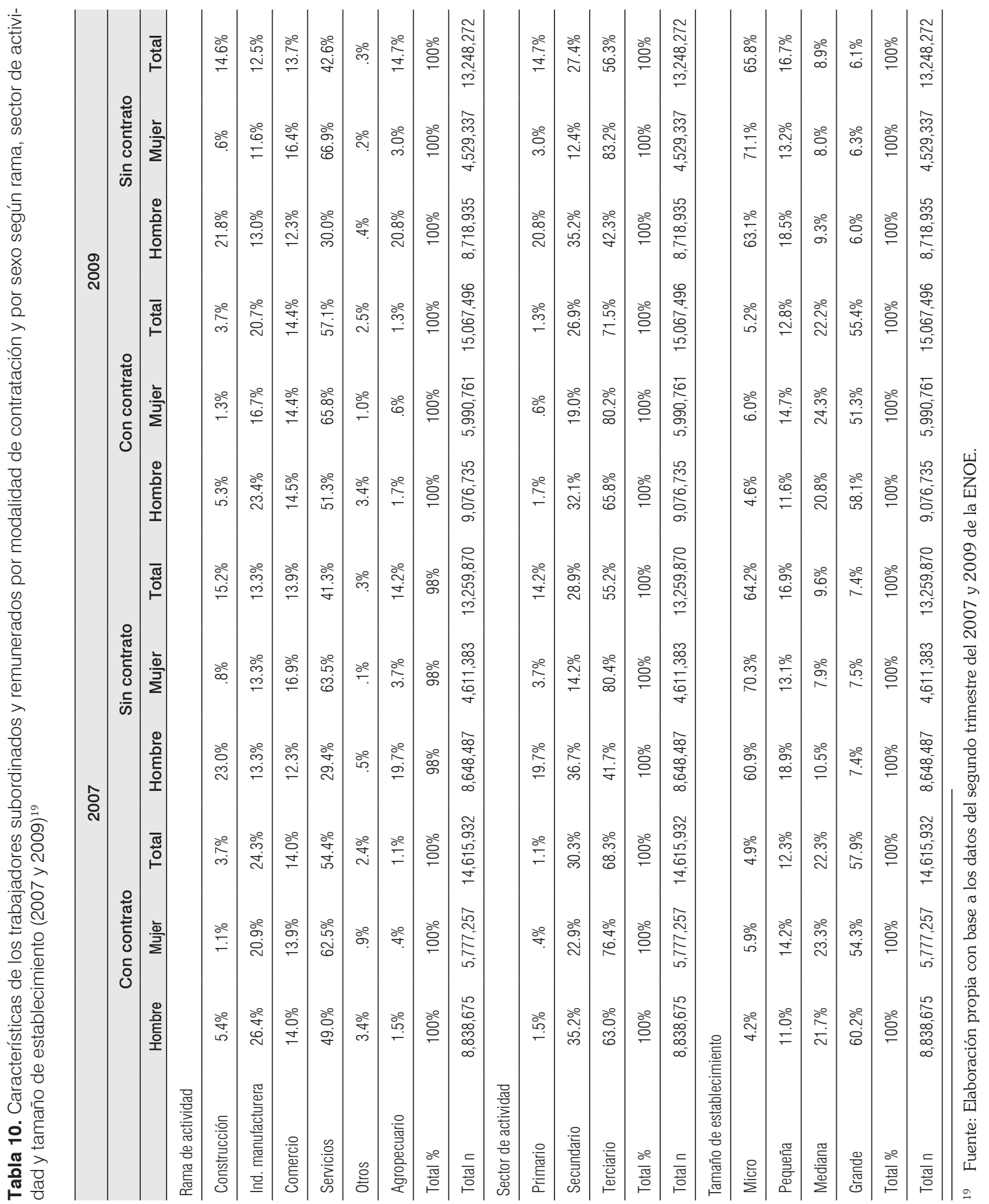




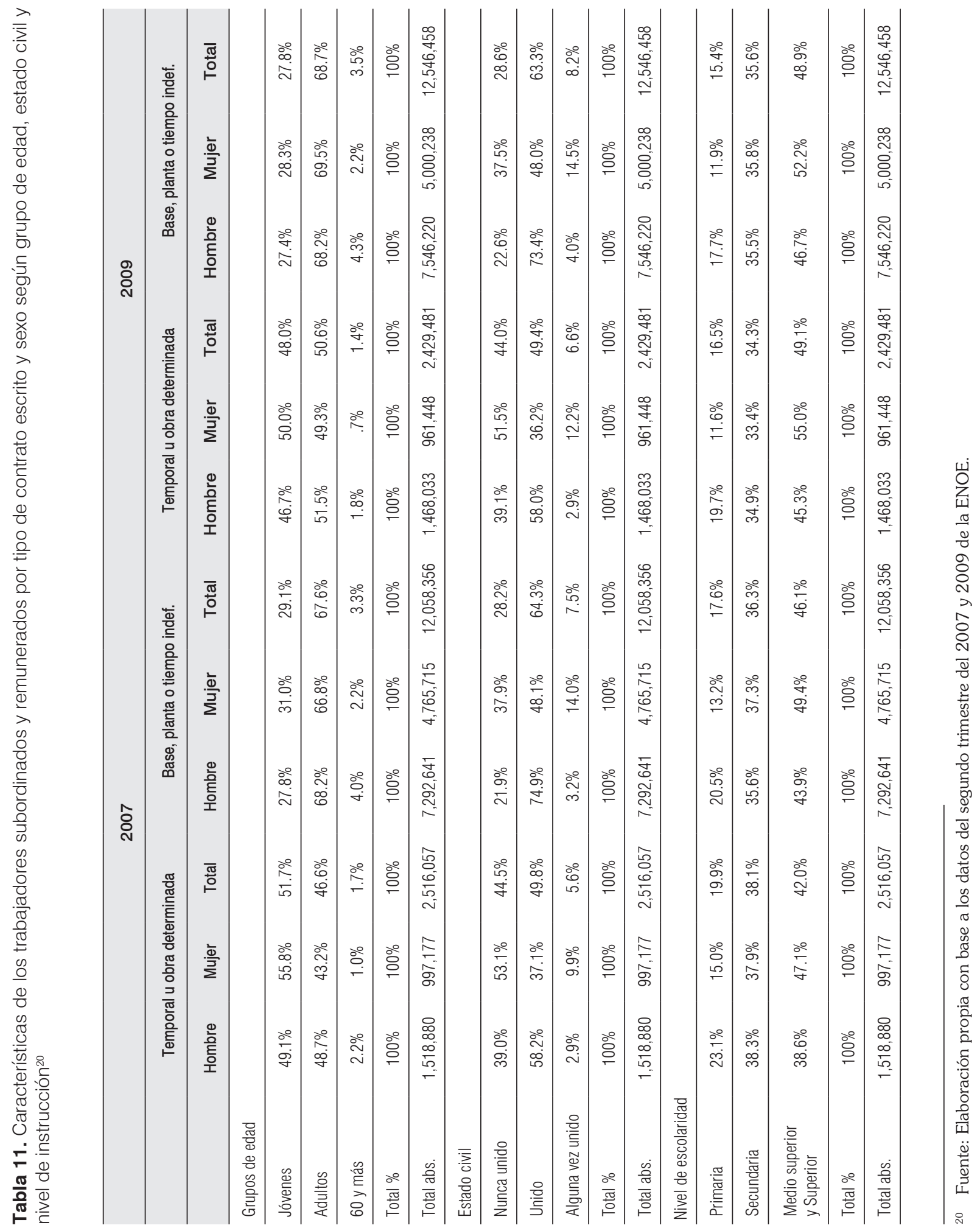




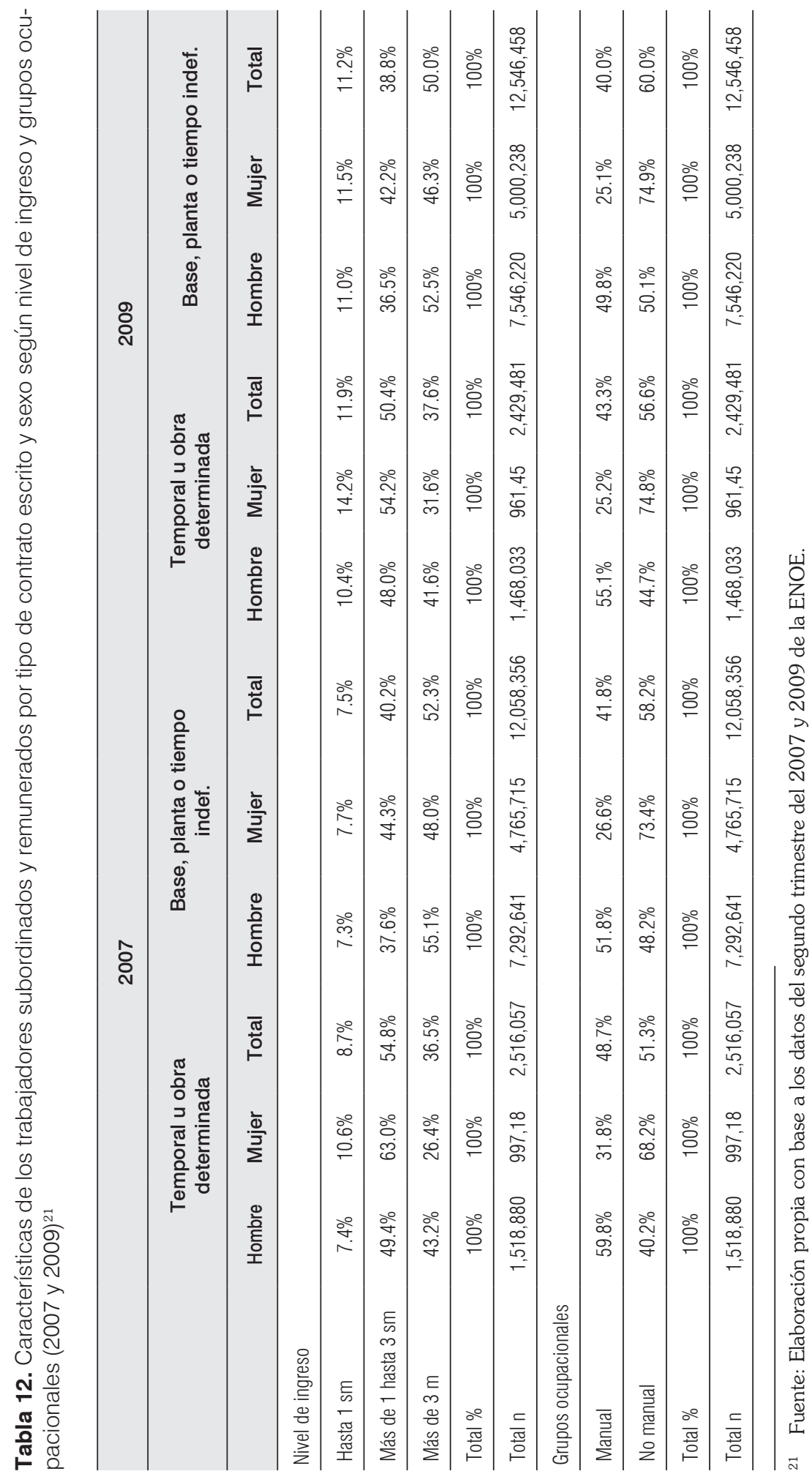




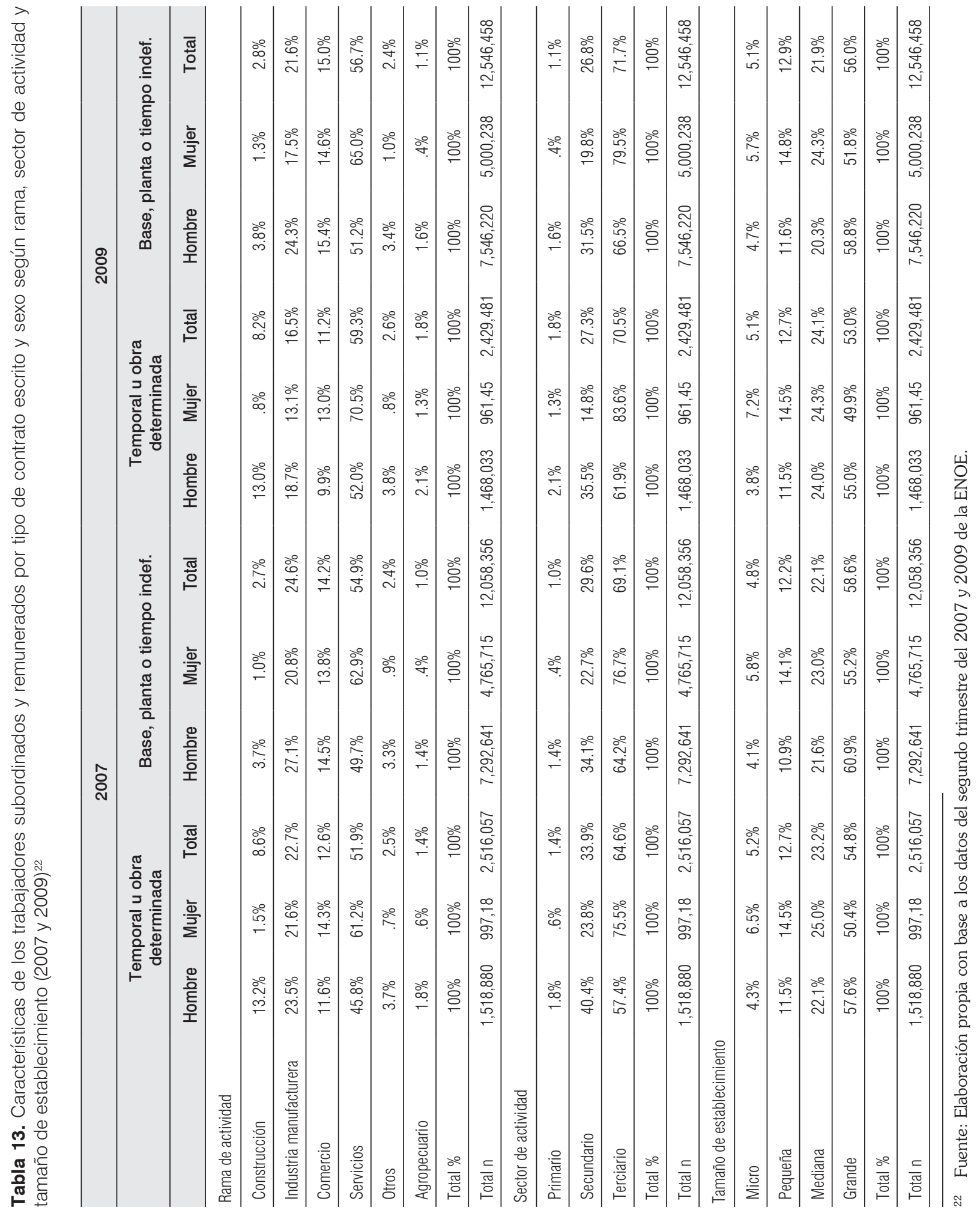

